\title{
Medical students risk disappointment when applying to both Canada and US for residency
}

\author{
— Cite as: CMAJ 2018 July 9;190:E844-5. doi: 10.1503/cmaj.109-5626
}

Posted on cmajnews.com on June 21, 2018.

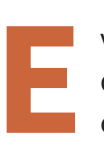
very year graduating medical students across Canada await the first of March with bated breath. That's the day they log into the CaRMS (Canadian Resident Matching Service) website to learn the results of the first of two iterations of the residency match. This year, like any other, it was a difficult day for those who didn't match.

But even among matched applicants, it can be bittersweet. Maybe they got into their specialty of choice but not their preferred program. Or perhaps they matched somewhere far from family and friends. And another group of matched applicants, those who also applied to the
United States through the NRMP (National Residency Matching Program), may have wondered where they might have matched south of the border.

In 2017, according to CaRMS, 26 Canadian medical graduates applied to the NRMP, and 44 US medical graduates submitted a ranked list to CaRMS. Students who applied to CaRMS and NRMP, which also include some international medical graduates, were forced, in effect, to rank every Canadian program over every American one. Since each match is binding and the systems are coordinated, applicants who match in Canada in the first iteration are automatically withdrawn from the US match. The results of the US match, which has only one iteration, are released on the third Friday of March, after the first iteration of the Canadian match.

Ranking both systems simultaneously was "frustrating," said an international medical graduate who matched in 2017 to his "back-up choice" of family medicine in Canada. The resident, who requested anonymity, was more interested in internal medicine and still wonders if he would have matched to an American internal medicine program. Allowing applicants to rank their preferred programs from both countries on the same list, rather than submitting separate lists to each match,

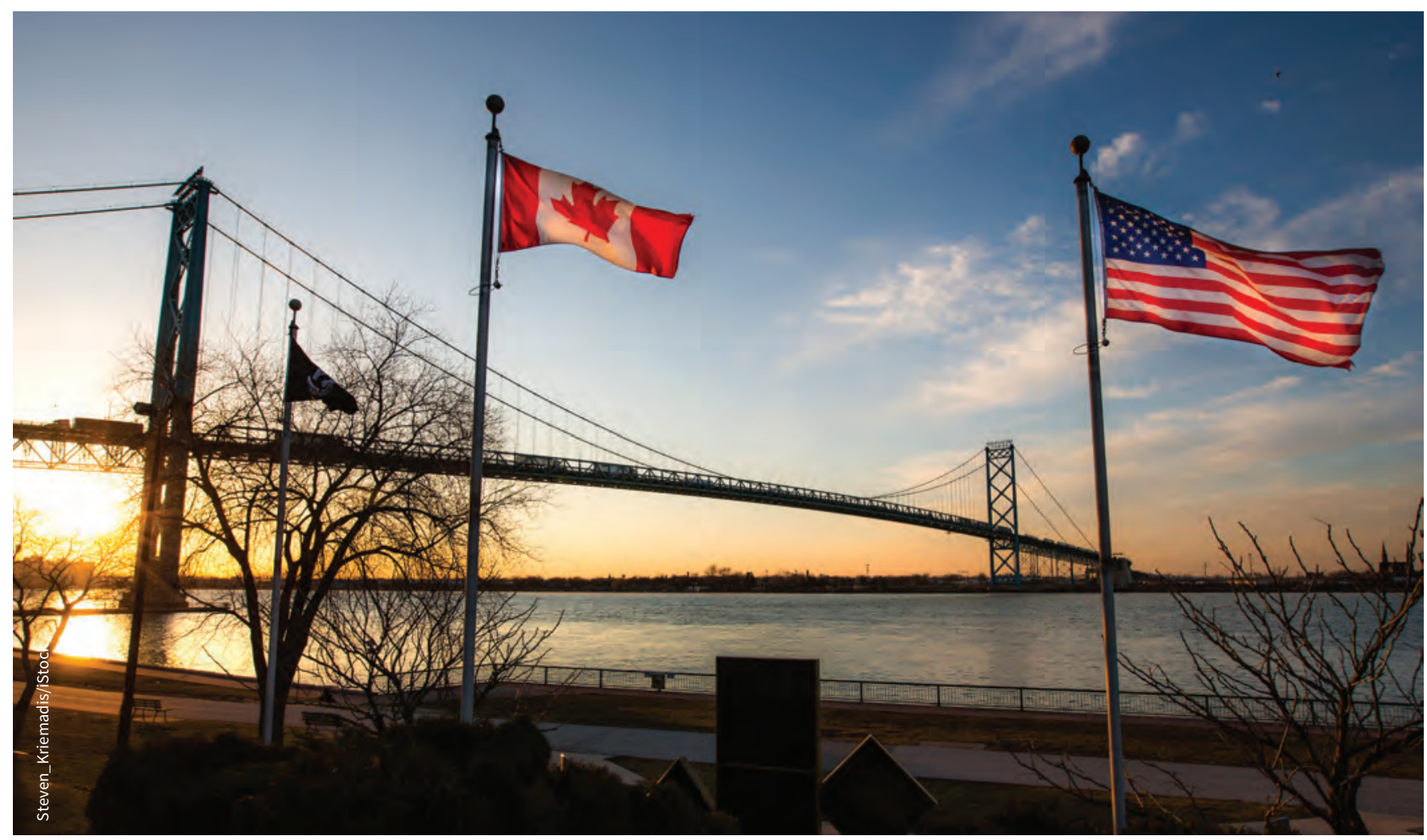

Medical students who apply for residencies in both Canada and US are automatically withdrawn from the US match if they first match in Canada. 
could be a potential solution to this dilemma, he said.

Some of the challenges to implementing a consolidated match are technical, such as the complexity of developing a shared matching algorithm. But perhaps the biggest challenge is that CaRMS and NRMP have different mandates since they are in countries with different health care needs.

"Our taxpayers are paying for a large proportion of our medical education," said Kaylynn Purdy, a fourth-year medical student speaking outside of her role as VP Education for the Canadian Federation of Medical Students, which does not have a position on this issue. "We're training to be physicians in Canada, so we should be encouraging students to stay in Canada."

Another issue, Purdy pointed out, is that more US medical graduates match to Canadian programs than vice versa, at a time when the number of unmatched Canadian medical graduates is growing. Last year, eight students from Canada went to the US, but 24 students from the US matched to Canada. "So, there's also an issue with US students matching in Canada because it's taking away our spots."

She added that she's "never heard a student complain about the way our match system works in terms of the timing - the Canadian one being before the US one," but added that she had never formally surveyed medical students on the topic.

This was echoed by Dr. Geneviève Moineau, president of the Association of Faculties of Medicine of Canada. "Certainly, from the perspective of those who are interested in both matches, I can appreciate it would be a lot easier if there was one match, but again it's not something l've heard from those students who are in Canada."

Dr. Mohsin Ali, Boston, Mass. 